\title{
KEPEMIMPINAN TRANSFORMASIONAL KEPALA SEKOLAH DALAM MENINGKATKAN MUTU GURU
}

\author{
Muhammad Hamzah Al Faruq \\ Supriyanto \\ Program Studi Manajemen Pendidikan, Fakultas IImu Pendidikan, Universitas Negeri Surabaya \\ muhammadalfaruq16010714060@unesa.ac.id
}

\begin{abstract}
Writing the article aims to analyze the role of the principal as a communicator, counselor, and consultant in improving the professional quality of teachers. In this study the authors used a literature study method of 25 journals divided into 15 international journals and 10 national journals. From some of these journals can be known that: 1) The role of the communicator in an effort to carry out quality assurance is by influencing his subordinates (parents of students, teachers, students, and administrative staff) to achieve their desires, given the importance of increasing the quality of students, therefore the principal's leadership is more emphasized in improving the professional quality of educators and the quality of graduates. 2) The role of counselor in an effort to improve teacher professionalism with education service users includes continuous improvement, having a vision and mission going forward, centering on student needs so that not only student performance is increased but also improving the quality and quality of the teaching profession itself. It can be concluded that the Principal Transformational leadership can improve. 3) The role of the principal's consultant in improving the professional quality of teachers is to be able to create fundamental changes for employees, teachers and students based on religious values, cultural systems to create innovation and the creativity of followers in achieving the vision and mission of the school.
\end{abstract}

Keywords: principal, principal leadership, principal transformational leadership, teacher professional quality

\begin{abstract}
Abstrak: Penulisan artikel bertujuan untuk menganalisis peran kepala sekolah sebagai komunikator, konselor, dan konsultan dalam meningkatkan mutu profesional guru. Dalam penelitian ini penulis menggunakan metode studi literatur terhadap 25 jurnal yang terbagi dari 15 jurnal internasional dan 10 jurnal nasional. Dari beberapa jurnal tersebut dapat diketahui bahwasanya : 1) Peran kepala sekolah sebagai komunikator dalam upaya melakukan penjaminan mutu adalah dengan memberi pengaruh terhadap bawahannya (orang tua peserta didik, guru, siswa, dan tenaga administrasi) untuk mencapai keinginan yang dicita-citakan, mengingat pentingnya meningkatkan kualitas peserta didik, oleh sebab itu kepemimpinan kepala sekolah lebih ditekankan dalam peningkatan mutu profesional pendidik serta mutu lulusan. 2) Peran kepala sekolah sebagai konselor dalam upaya meningkatkan profesional guru dengan pengguna jasa pendidikan meliputi perbaikan secara terus menerus, memiliki visi dan misi kedepan, berpusat pada kebutuhan siswa sehingga tidak hanya prestasi siswa saja yang meningkat melainkan juga meningkatkan mutu dan kualitas profesi guru itu sendiri. Dapat disimpulkan bahwa kepemimpinan Transformasional kepala sekolah dapat ditingkatkan. 3) Peran kepala sekolah sebagai konsultan kepala sekolah dalam meningkatkan mutu profesional guru adalah mampu menciptakan perubahan yang mendasar bagi karyawan, guru dan siswanya yang dilandasi dengan nilai-nilai agama, sistem budaya untuk menciptakan inovasi dan kreatifitas pengikutnya dalam mencapai visi misi sekolah.
\end{abstract}

Kata kunci: kepala sekolah, kepemimpinan kepala sekolah, kepemimpinan transformasional kepala sekolah, mutu guru

Saat ini, manusia sedang dalam era globalisasi, berbagai bidang ilmu pengetahuan telah mengalami perkembangan yang pesat. Salah satunya di bidang dunia pendidikan. Pendidikan termasuk sarana untuk memperoleh ilmu pengetahuan. Kehadiran ilmu pengetahuan maka seseorang dapat bertahan hidup serta dapat menghadapi tantangan zaman yang semakin maju. Pendidikan bisa diartikan sebagai usaha yang 
dilakukan untuk mengembangkan potensi dalam diri setiap individu. Menurut UndangUndang Republik Indonesia No 20 Tahun 2003 Tentang Sistem Pendidikan Nasional pada Pasal 1 Ayat 1 menjelaskan bahwasanya:

Pendidikan adalah suatu usaha yang dilakukan secara sadar dan terencana untuk mewujudkan suasana belajar ideal dan pembelajaran ideal, agar peserta didik secara aktif mengembangkan potensi yang ada dalam dirinya untuk memiliki kekuatan spiritual keagamaan, pPengendalian diri, kepribadian, Kecerdasan, Akhlak yang mulia, serta keterampilan lainnya yang diperlukan dirinya, masyarakat, bangsa dan negara.

Suatu mutu peserta didik perannya sangat penting dalam peningkatan pendidikan. Bahkan mutu peserta didik dapat diraih melalui pencapaian keberhasilan guru dalam mengajar serta membimbing peserta didik tersebut. Dalam Peraturan Pemerintah No. 19 tahun 2017 tentang Perubahan Peraturan Pemerintah No. 74 Tahun 2008 Pasal 1 yang mengatakan bahwasanya guru merupakan pendidik yang memiliki tugas utama dengan tanggung jawab secara profesional diantaranya yaitu melatih, membimbing, mengarahkan, mengajar, mendidik, menilai, dan mengevaluasi siswa mulai dari kelas terendah hingga menengah keatas yaitu pendidikan dasar dan pendidikan menengah atau pendidikan formal.

Penyebab rendahnya kualitas pendidikan di Indonesia yaitu sumber daya manusia yang masih memiliki kualitas pendidik di bawah rata-rata, sehingga mengakibatkan terhambatnya perkembangan serta pembangunan ekonomi nasional. Tahapantahapan yang perlu ditata sumber daya manusianya setidaknya memiliki kesinambungan dengan pendekataan pendidikan yang bermutu, baik pada jalur pendidikan informal, formal maupun non formal, mulai pendidikan dasar hingga pendidikan tinggi. Dalam dunia pendidikan yang perlu diperhatikan adalah metode pendidikan terhadap sumber daya manusia yang sampai sekarang mutu pendidikannya masih bisa dikatakan rendah karena berbagai keterangan memberikan petunjuk bahwasanya pendidikan di Indonesia belum bisa memberi hasil kepada sumber daya yang sesuai dengan perkembangan masyarakat dan kebutuhan pembangunan saat ini. Guru adalah bagian dari orang dimana dapat memberikan keberhasilan pada pendidikan di lembaga pendidikan karena guru adalah salah satu unsur sumber daya atau manusia yang sangat dekat hubungannya dengan siswa. Bahkan guru merupakan unsur penting di sebuah lembaga pendidikan karena kinerja guru menjadi penentu keberhasilan belajar siswa dan menentukan mutu lulusan di lembaga pendidikan yang bersangkutan.

Tugas profesional guru meliputi seluruh kegiatan dimulai dari merencanakan, melaksanakan, dan mengevaluasi pembelajaran. Seorang guru yang mampu mengendalikan profesionalitas yang tinggi akan menunjukkan cerminan sikap yang mental serta komitmennya terhadap perwujudan serta peningkatan mutu profesional melalui berbagai strategi khususnya untuk kepala sekolah.

Kepala sekolah yang baik adalah pemimpin yang dapat memenuhi standar. Standar seorang pemimpin dalam sekolah (kepala sekolah) diatur dalam Peraturan Menteri Pendidikan Nasional Nomor 13 Tahun 2007 tentang Standar Kepala Sekolah/Madrasah. Dalam standar kepala sekolah tersebut berisi mengenai kualifikasi umum kepala sekolah/madrasah, kualifikasi khusus kepala sekolah/madrasah, dan kompetensi. Mengingat pentingnya 3 standar tersebut maka setiap kepala sekolah pada lembaga atau institusi pendidikan di setiap jenjang pendidikan harus mampu mencapainya. Kualifikasi kepala sekolah di setiap jenjang dan satuan pendidikan berbeda-beda.

Fakta yang terjadi di lapangan menunjukkan banyak persoalan tentang kepala sekolah. Sesuai apa yang diungkapkan Hermawan, Koordinator Koalisi Pendidikan Kota Bandung bahwa, "banyak pemilihan kepala sekolah tidak memenuhi standar terutama di daerah yang masih minim sumber daya manusia yang mampu menjadi seorang pemimpin. Seharusnya perlu adanya sertifikat pendidik dan harus mengikuti pendidikan dan pelatihan untuk kepala sekolah. Sedangkan pada kenyataannya syarat tersebut belum mampu dipenuhi oleh pemerintah di daerah, tetapi pemberian jabatan kepala sekolah sudah banyak terealisasi" (Kompas, 24/7/2012). Selain itu, permasalahan lain juga muncul akibat dari tidak mampunya kepala sekolah dalam 
membimbing dan mengarahkan guru. Hal tersebut dapat dilihat dari nilai rata-rata nasional UKG (Uji Kompetensi Guru).

Dapat disimpulkan bahwa permasalahan muncul disebabkan kinerja kepala sekolah yang belum memenuhi standar. Kepemimpinan transformasional kepala sekolah dapat dilihat dari tiga peran yaitu, peran komunikator kepala sekolah dalam meningkatkan mutu dan kualitas professional guru, peran konselor kepala sekolah dalam meningkatkan mutu dan kualitas professional guru, dan peran konsultan kepala sekolah dalam meningkatkan mutu dan kualitas profesional guru. Dari hal tersebut maka dapat diyakini peran konselor kepala sekolah dalam meningkatkan mutu profesional guru juga berdampak pada kualitas suatu lulusan.

Wujud kepemimpinan transformasioanal kepala sekolah didasari dengan kualitas atau mutu pendidikan baik pula. Mengingat pentingnya meningkatkan kualitas peserta didik, oleh sebab itu kepemimpinan kepala sekolah lebih ditekankan dalam peningkatan mutu profesional pendidik serta mutu lulusan. Apabila pendidiknya memiliki kualitas yang baik maka kualitas peserta didik pun akan meningkat. Sedangkan dalam penelitian kepemimpinan transformasional adalah bentuk kepemimpinan yang mengoptimalkan semua potensi yang ada di lembaga tersebut untuk mencapai tujuan lembaga pendidikan atau sekolah, serta peningkatan mutu yang dilaksanakan oleh kepala sekolah terlihat dari respon masyarakat yang selalu meningkat.

Berdasarkan uraian yang telah dipaparkan diatas, penulis tertarik untuk mengkaji "Kepemimpinan Transformasional Kepala Sekolah Dalam Meningkatkan Mutu Guru”. Kepemimpinan transformasional kepala sekolah ditekankan pada upaya kepala sekolah mempengaruhi setiap bawahannya terutama para guru sehingga dapat diperoleh dukungan dari berbagai pihak untuk meningkatkan kualitas peserta didik.

\section{METODE}

Penelitian ini menggunakan metode penelitian studi literatur dengan menelaah dua puluh lima jurnal yang membahas tentang peran kepala sekolah dalam membangun mutu sekolah yang terdiri dari lima belas jurnal internasional dan sepuluh jurnal Nasional.
Tabel 1. Studi Literatur Jurnal

\begin{tabular}{|c|c|c|c|c|}
\hline No & $\begin{array}{l}\text { Nama } \\
\text { (Tahun) }\end{array}$ & $\begin{array}{c}\text { Judul } \\
\text { Penelitian }\end{array}$ & $\begin{array}{c}\text { Metode } \\
\text { Penelitia } \\
\mathbf{n}\end{array}$ & $\begin{array}{l}\text { Instrum } \\
\text { ent }\end{array}$ \\
\hline 1 & $\begin{array}{l}\text { Cahya } \\
\text { Pribadi, } \\
\text { Sisca. } 2014 .\end{array}$ & $\begin{array}{l}\text { perbedaan } \\
\text { tingkat dan } \\
\text { profesinalisme } \\
\text { guru kualitas proses } \\
\text { pembelajran } \\
\text { berdasarkan } \\
\text { latar belakang } \\
\text { pendidikan } \\
\text { sarjana guru } \\
\text { yang berbeda } \\
\text { di SMK } \\
\text { Program Studi } \\
\text { keahlian teknik } \\
\text { elektrnika dan } \\
\text { ketenagalistrika } \\
n \text { di kabupaten } \\
\text { karawang }\end{array}$ & $\begin{array}{l}\text { Kuantitati } \\
f\end{array}$ & $\begin{array}{l}\text { Observa } \\
\text { si, } \\
\text { wawanc } \\
\text { ara, } \\
\text { dokumen } \\
\text { tasi }\end{array}$ \\
\hline 2 & $\begin{array}{l}\text { Yuningsih, } \\
\text { Eri, Endang. } \\
2015 .\end{array}$ & $\begin{array}{l}\text { Kepemimpinan } \\
\text { Transformasion } \\
\text { al kepala } \\
\text { sekolah dan } \\
\text { iklim sekolah } \\
\text { terhadap } \\
\text { sekolah efektif } \\
\text { pada r SD } \\
\text { Negeri r di } \\
\text { Purwakarta }\end{array}$ & Kualitatif & $\begin{array}{l}\text { Observa } \\
\text { si, } \\
\text { wawanc } \\
\text { ara, } \\
\text { dokumen } \\
\text { tasi }\end{array}$ \\
\hline 3 & $\begin{array}{l}\text { Radi } \\
\text { Saputra. } \\
2018 .\end{array}$ & $\begin{array}{l}\text { Gaya } \\
\text { kepemimpinan } \\
\text { kepala sekolah } \\
\text { dalam } \\
\text { meningkatkan } \\
\text { jumlah } \\
\text { siswa/siswi di } \\
\text { SMP Negeri } 18 \\
\text { Kota jambi } \\
\end{array}$ & $\begin{array}{l}\text { Metode } \\
\text { kuantitati } \\
f\end{array}$ & $\begin{array}{l}\text { Kuesion } \\
\text { er dan } \\
\text { dokumen } \\
\text { tasi }\end{array}$ \\
\hline 4 & $\begin{array}{l}\text { Junaidah. } \\
2012 .\end{array}$ & $\begin{array}{l}\text { Kepemimpinan } \\
\text { Transformasina } \\
\text { I dalam } \\
\text { pendidikan }\end{array}$ & $\begin{array}{l}\text { Metode } \\
\text { literature }\end{array}$ & $\begin{array}{l}40 \text { artikel } \\
\text { penelitia } \\
n\end{array}$ \\
\hline 5 & $\begin{array}{ll}\text { Anjar, } & \text { Tri. } \\
2011 . & \end{array}$ & $\begin{array}{l}\text { Peranan } \\
\text { Konsultasi } \\
\text { Konselor } \\
\text { Sekolah }\end{array}$ & $\begin{array}{l}\text { Metode } \\
\text { literature }\end{array}$ & Artikel \\
\hline 6 & $\begin{array}{l}\text { Fadilla, Arvin } \\
\text { dan Imam } \\
\text { Arisudana. } \\
2009 .\end{array}$ & $\begin{array}{l}\text { Kepemimpinan } \\
\text { Transformasion } \\
\text { al, } \\
\text { Kepercayaan } \\
\text { dan berbagi } \\
\text { pengetahuan } \\
\text { dalam organisai }\end{array}$ & $\begin{array}{l}\text { Metode } \\
\text { kualitatif }\end{array}$ & $\begin{array}{l}\text { Observa } \\
\text { si, } \\
\text { wawanc } \\
\text { ara, } \\
\text { dokumen } \\
\text { tasi }\end{array}$ \\
\hline 7 & $\begin{array}{l}\text { Inayatullah. } \\
2011 .\end{array}$ & $\begin{array}{l}\text { Kontribusi } \\
\text { faktor-faktor } \\
\text { internal dan } \\
\text { eksternal } \\
\text { terhadap } \\
\text { peningkatan } \\
\text { kinerja } \\
\text { profesional } \\
\text { guru }\end{array}$ & $\begin{array}{l}\text { Metode } \\
\text { kualitatif }\end{array}$ & $\begin{array}{l}\text { Observa } \\
\text { si, } \\
\text { wawanc } \\
\text { ara, } \\
\text { dokumen } \\
\text { tasi }\end{array}$ \\
\hline 8 & $\begin{array}{l}\text { Fatinam, } \\
2016 .\end{array}$ & $\begin{array}{l}\text { Kepemimpinan } \\
\text { Transformasion } \\
\text { al kepala } \\
\text { sekolah dalam } \\
\text { peningkatan } \\
\text { profesionalisme } \\
\text { guru }\end{array}$ & $\begin{array}{l}\text { Metode } \\
\text { Kualitatif }\end{array}$ & $\begin{array}{l}\text { wawanc } \\
\text { ara, } \\
\text { observas } \\
\text { i, dan } \\
\text { studi } \\
\text { dokumen } \\
\text { tasi dan } \\
\text { deskriptif } \\
\text { analisis }\end{array}$ \\
\hline 9 & Yulianti, & Implementasi & Metode & Observa \\
\hline
\end{tabular}




\begin{tabular}{|c|c|c|c|c|}
\hline & Heni. 2018. & $\begin{array}{l}\text { kepemimpinan } \\
\text { transformasion } \\
\text { al kepala } \\
\text { sekolah dalam } \\
\text { meningkatkan } \\
\text { mutu } \\
\text { pembelajaran } \\
\text { di SD Negeri } 1 \\
\text { Simbarawarngi } \\
n \quad \text { kecematan } \\
\text { trimurjo } \\
\text { kabupaten } \\
\text { lampung } \\
\text { tengah }\end{array}$ & kualitatif & $\begin{array}{l}\text { si, } \\
\text { wawanc } \\
\text { ara, } \\
\text { dokumen } \\
\text { tasi }\end{array}$ \\
\hline 10 & $\begin{array}{l}\text { Suparno, } \\
\text { Danim. } 2009 .\end{array}$ & $\begin{array}{l}\text { Manajemen } \\
\text { dan } \\
\text { Kepemimpinan } \\
\text { Transformasion } \\
\text { al } \\
\text { Kekepalasekola } \\
\text { han (visi dan } \\
\text { strategi sukses } \\
\text { era teknologi, } \\
\text { situasi kritis, } \\
\text { dan Internal } \\
\text { Pendidikan) } \\
\end{array}$ & $\begin{array}{l}\text { Metode } \\
\text { kualitatif }\end{array}$ & $\begin{array}{l}\text { Dokume } \\
\text { ntasi, } \\
\text { observas } \\
\text { i, } \\
\text { wawanc } \\
\text { ara }\end{array}$ \\
\hline 11 & $\begin{array}{l}\text { Bass, } \\
\text { Bernard M. } \\
1990 .\end{array}$ & $\begin{array}{l}\text { From } \\
\text { Transactional } \\
\text { to } \\
\text { Transformation } \\
\text { al Leadership }\end{array}$ & $\begin{array}{l}\text { Metode } \\
\text { Rancang } \\
\text { aEx-post } \\
\text { Facto }\end{array}$ & $\begin{array}{l}\text { Wawanc } \\
\text { ara. } \\
\text { Observa } \\
\text { sidan } \\
\text { Koesion } \\
\text { er }\end{array}$ \\
\hline 12 & $\begin{array}{l}\text { Bakker, A.B., } \\
\text { Albrecht, S.L } \\
\text { and Leiter, } \\
\text { M.P. 2011. }\end{array}$ & $\begin{array}{l}\text { Key Questions } \\
\text { Regarding work } \\
\text { engagement, }\end{array}$ & $\begin{array}{l}\text { Metode } \\
\text { Literatur }\end{array}$ & $\begin{array}{l}\text { Dokume } \\
\text { ntasi dan } \\
\text { Artikel }\end{array}$ \\
\hline 13 & $\begin{array}{l}\text { Ismail. A. } \\
2009 .\end{array}$ & $\begin{array}{l}\text { The Mediating } \\
\text { Effect of } \\
\text { Empowerment } \\
\text { In the } \\
\text { Relationship } \\
\text { Betwen } \\
\text { Transformation } \\
\text { al Leadership } \\
\text { and service } \\
\text { Quality }\end{array}$ & $\begin{array}{l}\text { Metode } \\
\text { Kuantitati } \\
f\end{array}$ & $\begin{array}{l}\text { Koesion } \\
\text { erdan } \\
\text { Observa } \\
\text { si }\end{array}$ \\
\hline 14 & $\begin{array}{l}\text { Cohen, J.R. } \\
2006 .\end{array}$ & $\begin{array}{l}\text { An Examination } \\
\text { of The } \\
\text { Perceived } \\
\text { Impract of } \\
\text { Flexible Work } \\
\text { Arrangements } \\
\text { on Professional } \\
\text { Opportunities in } \\
\text { Public } \\
\text { Accounting }\end{array}$ & $\begin{array}{l}\text { Metode } \\
\text { Kuantitati } \\
f\end{array}$ & $\begin{array}{l}\text { Wawanc } \\
\text { ara dan } \\
\text { Survey }\end{array}$ \\
\hline 15 & $\begin{array}{l}\text { llies, R., } \\
\text { Nahrgang, } \\
\text { J.D. \& } \\
\text { Morgeson, } \\
\text { F.P. 2007. }\end{array}$ & $\begin{array}{l}\text { Leader member } \\
\text { exchange and } \\
\text { citizenship } \\
\text { behavior: A } \\
\text { met-analysis }\end{array}$ & $\begin{array}{l}\text { Metode } \\
\text { Kualitatif }\end{array}$ & $\begin{array}{l}\text { Observa } \\
\text { si, } \\
\text { Wawanc } \\
\text { ara dan } \\
\text { Dokume } \\
\text { ntasi }\end{array}$ \\
\hline 16 & $\begin{array}{l}\text { Xenikou, A. } \\
2017 .\end{array}$ & $\begin{array}{l}\text { Transformation } \\
\text { leadership: } \\
\text { Transactional } \\
\text { Contingent } \\
\text { Reward, and } \\
\text { oeganizational } \\
\text { Identification } \\
\text { the Mediating } \\
\text { Effect of } \\
\text { Perceived and } \\
\text { Inovation arientations } \\
\text { Goal Culture } \\
\text { Orien }\end{array}$ & $\begin{array}{l}\text { Metode } \\
\text { Kuantitati } \\
f\end{array}$ & $\begin{array}{l}\text { Wawanc } \\
\text { ara, } \\
\text { Observa } \\
\text { si dan } \\
\text { Koesion } \\
\text { er }\end{array}$ \\
\hline
\end{tabular}

\begin{tabular}{|c|c|c|c|c|}
\hline 17 & $\begin{array}{l}\text { Morrow, P. } \\
\text { C., Suzuki, } \\
\text { Y. } 2005 .\end{array}$ & $\begin{array}{l}\text { The Role of } \\
\text { Leader- } \\
\text { Member } \\
\text { exchange in } \\
\text { High turnover } \\
\text { work } \\
\text { environments }\end{array}$ & $\begin{array}{l}\text { Metode } \\
\text { Kuantitati } \\
f\end{array}$ & $\begin{array}{l}\text { Surve } \\
\text { dan } \\
\text { Florida }\end{array}$ \\
\hline 18 & $\begin{array}{l}\text { Sarros, J.C. } \\
2002 .\end{array}$ & $\begin{array}{l}\text { The Leadership } \\
\text { and its impact } \\
\text { on } \\
\text { Organizational } \\
\text { Culture. }\end{array}$ & Kualitatif & $\begin{array}{l}\text { Dokume } \\
\text { ntasi, } \\
\text { Survey } \\
\text { dan } \\
\text { Sample }\end{array}$ \\
\hline 19 & $\begin{array}{l}\text { Avolio, B., } \\
\text { Waldan, D. \& } \\
\text { Yammario, } \\
\text { F. 1991. }\end{array}$ & $\begin{array}{l}\text { Leading i the } \\
\text { 1990's the four } \\
\text { l's of } \\
\text { transformationa } \\
\text { I leadership. }\end{array}$ & $\begin{array}{l}\text { Metode } \\
\text { Campura } \\
n\end{array}$ & $\begin{array}{l}\text { Docume } \\
\text { ntasi, } \\
\text { Wawanc } \\
\text { ara, } \\
\text { Koesion } \\
\text { er dan } \\
\text { Sample }\end{array}$ \\
\hline 20 & $\begin{array}{l}\text { Saks. Alan } \\
\text { M. 2006, }\end{array}$ & $\begin{array}{l}\text { Employee } \\
\text { Engagement: } \\
\text { Antecendents } \\
\text { and } \\
\text { Consequences }\end{array}$ & $\begin{array}{l}\text { Metode } \\
\text { Kualitatif }\end{array}$ & $\begin{array}{l}\text { Docume } \\
\text { ntasi, } \\
\text { Survey }\end{array}$ \\
\hline 21 & $\begin{array}{l}\text { Judge. T. A } \\
\text { and piccolo. } \\
\text { R. F. } 2004 .\end{array}$ & $\begin{array}{l}\text { Transformation } \\
\text { al and } \\
\text { transactional } \\
\text { leadership: A } \\
\text { Meta-Analytic } \\
\text { Test of Their } \\
\text { Relative } \\
\text { Validity }\end{array}$ & Kualitatif & $\begin{array}{l}\text { Docume } \\
\text { ntasi, } \\
\text { Survey }\end{array}$ \\
\hline 22 & $\begin{array}{l}\text { Mahdinezha } \\
\text { d. M. } 2013 .\end{array}$ & $\begin{array}{l}\text { Transformation } \\
\text { al Transactional } \\
\text { leadership } \\
\text { Styles and Job } \\
\text { Performance of } \\
\text { academic } \\
\text { Leaders }\end{array}$ & Kualitatif & $\begin{array}{l}\text { Dokume } \\
\text { ntasi, } \\
\text { Survey } \\
\text { dan } \\
\text { Sample }\end{array}$ \\
\hline 23 & $\begin{array}{ll}\text { Hsu, S. } & \& \\
\text { Mutjaba, } & \text { B. } \\
\text { G. 2007. } & \end{array}$ & $\begin{array}{l}\text { Team } \\
\text { Transformation } \\
\text { al Leadership, } \\
\text { Trust, } \\
\text { Satisfaction, } \\
\text { And } \\
\text { Commitment: } \\
\text { The Testing of } \\
\text { A Structural } \\
\text { Equation Model } \\
\text { In Software } \\
\text { Development } \\
\text { Teams }\end{array}$ & Kualitatif & $\begin{array}{l}\text { Dokume } \\
\text { ntasi, } \\
\text { Survey } \\
\text { dan } \\
\text { Sample }\end{array}$ \\
\hline 24 & $\begin{array}{ll}\text { Yang } & \text { Y. } \\
2013 . & \end{array}$ & $\begin{array}{l}\text { Principals' } \\
\text { Transformation } \\
\text { al Leadership in } \\
\text { School } \\
\text { Improvement }\end{array}$ & Literature & Artikel \\
\hline 25 & $\begin{array}{l}\text { Normianti. } \\
\text { Aslamiah } \\
\text { and Suhaimi. } \\
2019 .\end{array}$ & $\begin{array}{l}\text { Relationship of } \\
\text { transformationa } \\
\text { I Leader of } \\
\text { Principal } \\
\text { Teacher } \\
\text { Motivation, } \\
\text { Teacher } \\
\text { Organization } \\
\text { Commitments } \\
\text { with } \\
\text { Performance of } \\
\text { Primary School } \\
\text { Teachers in } \\
\text { Labuan Amas } \\
\text { Selatan } \\
\text { Indonesia }\end{array}$ & Literature & Artikel \\
\hline
\end{tabular}


HASIL DAN PEMBAHASAN

\section{Peran Kepala Sekolah sebagai Komunikator dalam Membangun Mutu Sekolah}

Danim (2009:50) menjelaskan bahwa kepemimpinan transformasional kepala sekolah dapat diartikan sebagai gaya atau bentuk yang diterapkan kepala sekolah dalam memberi pengaruh terhadap bawahannya (orang tua peserta didik, guru, siswa, dan tenaga administrasi) untuk mencapai keinginan yang dicita-citakan. Berdasarkan pendapat tersebut dapat diketahui bahwa kepemimpinan transformasional kepala sekolah merupakan bentuk kepemimpinan yang mendorong semua unsur yang ada di sekolah (staf TU, guru, siswa, dan staf lainnya, masyarakat, orang tua siswa, dan stakeholder lainnya) agar bersedia bekerjasama, berpartisipasi secara optimal dalam rangka mewujudkan visi, tanpa ada unsur paksaan, dan bergotong-royong membangun masa depan dan menuju perubahan yang lebih baik terhadap suatu lembaga pendidikan atau sekolah. Pemimpin transformasional mampu mengubah keyakinan, sikap, dan tujuan pribadi masingmasing bawahan demi mencapai tujuan, bahkan melampaui tujuan yang disepakati (Ismail, 2009). Dalam penelitian Mahdinezhad (2013) menjelaskan bahwa kepemimpinan tranformasional adalah berfokus pada hubungan yang terbentuk antara pemimpin dan pengikutnya.

Dalam penelitian (Hsu \& Mutjaba. 2007:3) bahwa komunikasi memegang peranan penting di dalam keberhasilan membangun hubungan yang baik dengan bawahan. Hubungan yang baik akan menciptakan kepercayaan, sikap dan loyalitas yang positif (Morrow, dkk, 2005)

Berdasarkan studi pendahuluan terkait kepemimpinan transformasional kepala sekolah dapat diketahui sebagaimana dinyatakan oleh wakasek kurikulum sebagai berikut : "Kepemimpinan kepala sekolah memang sangatlah luar biasa untuk bisa membawa perubahan yang tadinya anak desa yang kurang peduli akan pentingnya pendidikan sekarang jadi tahu akan pentingnya pendidikan bagi mereka. Dengan di tingkatkannya eksistensi pembelajaran serta motivasi kepada guru dan siswa dapat berdampak positif bagi siswa dan mengakibatkan banyaknya perubahan pada siswa. Berbagai perbaikan dilakukan oleh kepala sekolah agar dapat meningkatkan mutu sekolah tersebut. Cohen (2006) beranggapan bahwa kerja yang berpotensi positif sangat dipengaruhi oleh kinerja yang baik.

Menurut Sarros (2002) kepemimpinan transformsional merupakan jenis kepemimpinan yang membangkitkan kesadaran para pengikut dengan menunjukkan nilai-nilai dan cita-cita yang tinggi seperti kebebasan, keadilan dan kesetaraan. Wujud kepemimpinan transformasional kepala sekolah didasari dengan kualitas atau mutu pendidikan baik pula. Mengingat pentingnya meningkatkan kualitas peserta didik, oleh sebab itu kepemimpinan kepala sekolah lebih ditekankan dalam peningkatan mutu profesional pendidik serta mutu lulusan. Apabila pendidiknya memiliki kualitas yang baik maka kualitas peserta didik pun akan meningkat. Kepemimpinan transformasional kepala sekolah adalah kunci untuk mendorong perkembangan sekolah. Ini dapat membantu sekolah memecahkan masalah secara konsisten dan mendapatkan berbagai tingkat perbaikan pada tahap yang berbeda (Yang, 2013).

Yulianti (2018:82) menyatakan bahwa kepala sekolah dalam berperan harus menjadi sebuah agen perubahan agar sekolah yang dipimpin lebih berkembang dari sebelumnya. Kepala sekolah memiliki peran yang besar dalam kemajuan sekolah yang dipimpinnya. Kepemimpinan transformasional dapat dijabarkan melalui perilaku kharismatik-ideal, inspiratif, memiliki intelektual yang tinggi, serta memberikan perhatian serta melatih, dan menasihati karyawan secara individual sehingga dapat meningkatkan mutu sekolah tersebut. Saks (2006) ketika seorang guru atau bawahan dari kepala sekolah tersebut menyenangi pekerjaannya maka karyawan tersebut juga akan terlibat secara aktif dalam pekerjaannya dan bekerja dengan rekanrekannya untuk meningkatkan kinerja dalam pekerjaan untuk kepentingan organisasi atau lembaga pendidikan tersebut.

\section{Peran Kepala Sekolah sebagai Konselor dalam Meningkatkan Mutu Profesional Guru}

Anjar (2011:61) menjelaskan bahwa bagi pimpinan sekolah. Kesulitan dalam 
mengerjakan tugas belajar kepemimpinan dapat diartikan sebagai sebuah kemampuan yang menimbulkan rasa percaya diri pada karyawan, rasa percaya diri yang timbul pada karyawan dapat memicu kemajuan dan tercapainya tujuan organisasi, sehingga tugas seorang pemimpin juga menjaga keutuhan kerjasama tim yang bekerja pada organisasi tersebut. Kepemimpinan juga bisa diartikan sebagai bentuk kualitas suatu kelompok atau organisasi. Sebuah Organisasi atau kelompok adanya tujuan yang ingin dicapai bersama dalam sebuah kelompok. Pencapaian itu akan sangat efektif jika mengikutsertakan semua unsur elemen didalamnya. Untuk mengkondisikan semua anggota didalam sebuah kelompok memerlukan seorang pemimpin yang dapat mengelompokkan setiap anggotanya dan mengarahkan pada Tugas pokok, fungsi, dan deskripsinya masing masing. Normianti dan Suhaimi (2019:5) menjelaskan bahwa kepemimpinan transformasional juga sangat penting untuk membangkitkan komitmen yang lebih tinggi pada anggotanya untuk lebih mementingkan kepentingan suatu organisasi tersebut.

Menurut Junaidah (2012:117) kepemimpinan merupakan bagian penting dari manajemen yaitu merencanakan dan mengorganisasi, tetapi peran utama kepemimpinan adalah mempengaruhi orang lain untuk mencapai tujuan yang telah ditetapkan. Karakteristik kepemimpinan adalah pengaruh yang signifikan untuk perusahaan atau kinerja organisasi (Avolio, dkk 1991). Kepala sekolah mampu mengerakan karyawan dengan cara memberi reward kepada karyawan dan guru terbaik di sekolah tersebut setiap tahunnya. Pemberian tersebut bertujuan untuk memotivasi para karyawan dan guru agar lebih optimal lagi dalam menjalankan tugasnya. Prilaku tersebut juga sesuai dengan penelitian Fatinam (2016:13) bahwa faktor-faktor yang mendukung kepala sekolah dalam peningkatan profesionalisme guru adalah dengan adanya peningkatan kesejahteraan guru dan tunjangan sertifikasi

Kepala sekolah yang memenuhi indikator transformasional ialah kepala sekolah yang memiliki peran konselor dalam membangun mutu dan kualitas, Kepemimpinan Transformasional adalah semua hal yang bersifat perbaikan secara terus menerus, memiliki visi dan misi kedepan, berpusat pada kebutuhan siswa sehingga tidak hanya prestasi siswa saja yang meningkat melainkan juga meningkatkan mutu dan kualitas profesi guru itu sendiri. Pribadi. (2014:3) menyatakan pendidikan guru berpengaruh pada profesionalisme guru dan kualitas proses pembelajaran karena hal tersebut sangat mempengaruhi pendidikan guru terhadap profesionalisme guru dan kualitas proses.

Bass dan Avolia berpendapat bahwa Kepemimpinan Komponen transformasional ada 4 macam yaitu: a) Idealized influence, mengubah jati diri setiap orang untuk memunculkan rasa hormat (respect) dan rasa percaya diri (trust) dari orang-orang yang dipimpinnya, sedangkan makna dari Idealized influence adalah saling berbagi persoalan atau resiko yang di hadapi oleh setiap kelompok, mulai dari persoalan pertanggung jawaban atas perilaku moral serta etis, dan kebutuhan pribadinya; b) Inspirational motivation, yang tercermin di dalam lingkungan yang senantiasa menyediakan sesuatu yang menantang dan senantiasa memberikan arti dari sebuah tanggung jawab orang-orang yang dipimpin, yang di dalamnya adalah sikap pemimpin yang dapat menghasilkan kerja nyata yang jelas dan perilaku yang mampu mendemonstrasikan komitmen dan dukungan terhadap tujuan organisasi. Bahkan Bakker, dkk (2011) mengklaim secara konseptual bahwa makna kerja dapat memediasi hubungan antara kepemimpinan transformasional dan keterlibatan kerja, oleh sebab itu perlu adanya antusiasme dan optimisme untuk membangun semangat para bawahannya; c) Intellectual simulation. Pemimpin yang menggunakan metode kepemimpinan yang mencari atau inovasi-inovasi baru dan mengggunakan cara penyelesaian yang kreatif dari orang-orang yang dipimpinnya. la juga selalu memberikan arahan atau suatu pendekatan baru dalam melakukan sebuah tanggung jawab; d) Individualized consideration, yaitu refleksi yang di lakukan oleh pemimpin yang selalu memperhatikan dan menjunjung tinggi kepada mereka yang memiliki prestasi dan selalu memperhatikan kebutuhan dari orang-orang yang dipimpinnya.

Fadilla dan Arisudana (2009:103) menyatakan bahwa ketika seoarng pemimpin belum mendapatan kepercayaan dari bawahannya, maka stimulasi yang dilakukan pemimpin terhadap bawahannya itu belum 
maksimal dan masih kurang berperan dalam membentuk prilaku yang baik. Sebagai akibat dari perlakuan seorang pemimpin yang menyenangkan menjadi timbal balik dari kinerja bawahannya. (Ilies, dkk 2007).

\section{Peran Kepala Sekolah sebagai Konsultan dalam Mengingkatkan Mutu Profesional Guru}

Menurut Danim (2009:62) indikator kepemimpinan transformasional sebagai berikut: a) pembaruan sistem, b) meneladani, c) memberi semangat dalam kemampuan kerja bawahan, d) menyesuaikan dengan lingkungan kerja, e) mengupayakan tanggung jawab bawahan, f) memberi semangat atas sistem nilai, g) pantang menyerah dan terus berusaha, dan $\mathrm{h}$ ) mampu mengatasi masalah.

Salah satu peran penting dalam mewujudkan sekolah yang bermutu adalah kepiawanan kepala sekolah dalam memimpin. Menurut Inayatullah (2011:71) ada beberapa hal yang di rekomendasikan yang berkaitan dengan komiten yaitu : pertama, motivasi atau keterbukaan dalam meningkatkan mutu, kedua, Tanggung Jawab dalam meningkatkan mutu, Ketiga kepercayaan meliputi, kepercayaan para guru dan karyawan non edukatif terhadap kepala sekolah.

Kepala sekolah menjadi seorang pembaru dengan melakukan berbagai perbaikan dari segala hal misalnya perubahan kurikulum, perbaikan sarana prasaran meliputi memperbaiki perpus, perbaikan ruang kelas, perbaikan ruang wakasek, perbaikan ruang loby tamu, perbaikan ruang TU, dan lain-lain. Perubahan sistem dilakukan kepala sekolah untuk meningkatkan kualitas dan meningkatkan setiap sistem agar lebih optimal. Dalam meningkatkan mutu dan perbaikan SDM maka kepala sekolah melakukann perbaikan dengan cara menginstruksikan para guru dan karyawan melalui kegiatan pelatihan, workshop dengan mendatangkan narasumber yang sudah ahli dalam bidangnya.

Hal ini juga sesuai dengan pendapat para ahli tentang Kepemimpinan transformasional dapat dikatakan berupaya menggiring SDM yang dipimpin ke arah tumbuhnya sensitivitas pembinaan dan pengembangan organisasi, pengembangan visi secara bersama, pendistribusian kewenangan kepemimpinan, dan membangun kultur organisasi sekolah yang menjadi keharusan bagi perbaikan perolehan belajar pada siswa. Xenikou (2017) menjelaskan bahwa upaya yang dapat dilakukan oleh kepala sekolah dalam rangka mempertahankan dan meningkatkan gaya kepemimpinan transformasional adalah melalui keteladan, kewibawaan, peningkatan pemberian motivasi, memantapkan kemampuan dan keterampilan berkomunikasi, pendelegasian dan pemberdayaan, serta pemberian bimbingan.

Keteladanan kepala sekolah ditunjukkan melalui berbagai hal yang dilakukan oleh setiap kepala sekolah misalnya dengan berangkat pagi ke sekolah tanpa terlambat, apabila ada sampah yang terlihat oleh beliau, beliau langsung membuang sampah pada tempatnya tanpa menyuruh orang lain melakukannya, selain itu jika ada sesuatu yang tidak pada tempatnya maka beliau akan turun tangan tanpa menunggu lama karyawannya melakukan hal tersebut, menginstruksikan apel pagi kepada para siswanya. Hal ini membuat karyawannya merasa malu dan lebih memahami perannya. Berbagai sikap yang ditunjukkan kepala sekolah tersebut dapat menjadikan kepala sekolah memperoleh rasa hormat dari bawahannya, seperti pendapat (Normianti \& Suhaimi. 2019) bahwa seorang kepala sekolah harus mampu mewujudkan kreatifitas, pencapaian prestasi, dan komunikasi seperti tepat waktu kedatangan ke sekolah dan tepat waktu pulang dari sekolah, kualitas hasil kerja baik dan ketika terjadi permasalahan yang rumit di sekolah maka kepala sekolah tanggap dan cepat dalam mengatasi permasalahan tersebut yaitu, dengan mengumpulkan semua karyawan, guru dan staf manajemen untuk melakukan rapat dan mencari solusinya secara bersama agar lebih baik kedepannya. Hal tersebut sesuai dengan pendapat Saputra (2018:71) dalam penelitiannya bahwa suatu organisani akan mengalami keberhasilan sebagian besar ditentukan oleh gaya kepemimpinannya dengan menggunakan kepemimpinan yang ideal pada saat situasi yang mendukung dan dapat memenuhi kinerja kepemmpinan dalam hal memberikan nasihat dan solusi. menurut (Ismail. 2009) Gaya kepemimpinan ialah pola pola perilaku pemimpin yang digunakan untuk mempengaruhi aktivitas orang-orang yang dipimpin untuk mencapai tujuan dalam suatu situasi organisasinya yang dapat berubah. 


\section{PENUTUP \\ Keimpulan}

Berdasarkan apa yang telah dipaparkan diatas, dapat disimpulkan sebagai berikut:

1. Peran kepala sekolah sebagai komunikator dalam upaya melakukan penjaminan mutu adalah dengan memberi pengaruh terhadap bawahannya (orang tua peserta didik, guru, siswa, dan tenaga administrasi) untuk mencapai keinginan yang di citacitakan, mengingat pentingnya meningkatkan kualitas peserta didik, oleh sebab itu kepemimpinan kepala sekolah lebih ditekankan dalam peningkatan mutu profesional pendidik serta mutu lulusan.

2. Peran kepala sekolah sebagai konseler dalam upaya meningkatkan profesional guru dengan pengguna jasa pendidikan meliputi perbaikan secara terus menerus, memiliki visi dan misi kedepan, berpusat pada kebutuhan siswa sehingga tidak hanya prestasi siswa saja yang meningkat melainkan juga meningkatkan mutu dan kualitas profesi guru itu sendiri. Dapat di simpulkan bahwa kepemimpinan Transformasional kepala sekolah dapat meningkatkan mutu dan kualitas guru serta lulusan.

3. Peran kepala sekolah sebagai konsultan kepala sekolah dalam meningkatkan mutu profesioanal guru adalah mampu menciptakan perubahan yang mendasar bagi karyawan, guru dan siswanya yang dilandasi dengan nilai-nilai agama, sistem budaya untuk menciptakan inovasi dan kreatifitas pengikutnya dalam mencapai visi misi sekolah.

\section{Saran}

Berdasarkan apa yang telah disimpulan di atas, maka hal yang dapat disarankan dari penelitian tentang kepemimpinan transformasional kepala sekolah dalam membangun mutu profesional guru adalah sebagai berikut:

1. Keteladan yang dilaksanakan oleh kepala sekolah selama ini sudah baik, namun alangkah lebih baiknya jika keteladana tersebut dijadikan sebuah upaya untuk mengkader pemimpin yang lebih baik lagi. Dengan adanya pengkaderan tersebut maka diharapkan akan ada sosok yang lebih baik lagi untuk meningkatkan mutu profesional guru secara berkelanjutan.
2. Dalam meningkatkan kualitas SDM yang baik alangkah lebih baiknya membuat inovasi-inovasi baru lagi dalam meningkatkan mutu SDM tersebut, agar tidak hanya sekedar pelatihan atau workshop saja, lebih baiknya inovasi baru tersebut dalam lebih meningkatkan mutu SDM dan dapat dilakukan secara terus menerus.

\section{DAFTAR PUSTAKA}

Avolio, B., Waldan, D. \& Yammario, F. 1991. Leading the 1990's the four I's of transformational leadership. Journal of European Industrial Training, 5.

Anjar, T. 2011. Peranan Konsultasi Konselor Sekolah. Jurnal GUIDENA. Vol.1. No.1. Universitas Muhammadiyah Metro.

Bakker, A.B., Albrecht, S.L \& Leiter, M.P. 2011. Key Questions Regarding work engagement. European Journal of Work and Organizational Psychology, Vol 20 No 1, pp.4-28.

Cohen, J.R. 2006. An Examination of The Perceived Impract of Flexible Work Arrangements on Professional Opportunities in Public Accounting. Journal of Business Ethics, Vol. 32 No. 4, pp. 317.

Danim. 2009. Manajemen dan Kepemimpinan Transformasional Kekepalasekolahan (visi dan strategi sukses era teknologi, situasi kritis, dan Internal Pendidikan). Jakarta: Rineka Cipta.

Fatinam, $2016 . \quad K e p e m i m p i n a n$ Transformasional Kepala Sekolah Dalam Peningkatan Profesionalisme Guru. Penelitian Program Studi Magister Administrasi Pendidikan FKIP. Untan Pontianak

Fadilla, A. \& Arisudana, I. 2009. Kepemimpinan Transformasional, Kepercayaan dan Berbagi Pengetahuan Dalam Organisasi. Jurnal Psikologi. Vol.36, No.2. Yogyakarta: Universitas Gadjah Mada.

Hsu, S. \& Mutjaba, B.G. 2007. Team Trans formational Leadership, Trust, Satisfaction And Commitment: The Testing of A Structural Equation Model In Software Development Teams. Review of Business 
Information Systems-Third Quarter. 2007 Volume 11, Number 3.

Inayatullah. 2011. Kontribusi Faktor-Faktor Internal dan Eksternal Terhadap Peningkatan Kinerja Profesional Guru. Jurnal Edukasi. Vol.3, No.1.

Ismail. A. 2009. The Mediating Effect of Empowerment In The Relationship Betwen Transformational Leadership and Service Quality. International Journal of Business and Management, Vol. 4, No. 4.

llies, R., Nahrgang, J.D. \& Morgeson, F.P. 2007. Leader Member Exchange and Citizenship Behavior: A Meta-Analysis. Journal of Applied Psycology. 92.

Junaidah 2012.

Kepemimpinan Transformasinal dalam pendidikan. Penelitian. Fakultas Tarbiyah dan Keguruan IAIN Raden Intan Lampung

Mahdinezhad. M. 2013. Transformational Transactional leadership Styles and Job Performance of academic Leaders. Journal International Education Studies. Vol. 6 No. 11.

Morrow, P. C., Suzuki, Y. 2005. The Role of Leader-Member Exchange in High Turnover Work Environments. Journal of managerial Psychology. 20

Normianti. A. \& Suhaimi. 2019. Relationship of Transformational Leader of Principal Teacher Motivation, Teacher Organization Commitments with Performance of Primary School Teachers in Labuan Amas Selatan Indonesia. European Journal of Education Studies. Vol.5.

Pribadi, S.C. 2014. Perbedaan Tingkat Profesinalisme Guru Dan Kualitas Proses Pembelajaran Berdasarkan Latar Belakang Pendidikan Sarjana Guru Yang Berbeda di SMK Program Studi Keahlian Teknik Elektronika dan Ketenagalistrikan di Kabupaten Karawang. Jurnal syiar nathiq. Karawang : Universitas Pendidikan Indonesia.

Saputra, R. 2018. Gaya kepemimpinan kepala sekolah dalam meningkatkan jumlah siswa/siswi di SMP Negeri 18 Kota jambi. Penelitian Prodi manajemen pendidikan Islam Universitas Thaha Saifuddin.
Saks, A.M. 2006. Employee Engagement: Antecendents and Consequences. Journal of Managerial Psychology. Vol. 21, No. 7. Pp. 600-619.

Sarros, J.C. 2002. The Leadership and its impact on Organizational Culture. International Journal of Business Studies. Vol. 10 No.2.

Xenikou, A. 2017. Transformation leadership: Transactional Contingent Reward, and oeganizational Identification the Mediating Effect of Perceived Inovation and Goal Culture Orientations. Fronties in Psycology.

Yulianti, H. 2018. Implementasi Kepemimpinan Transformasional Kepala Sekolah Dalam Meningkatkan Mutu Pembelajaran di SD Negeri 1 Simbarawarngin Kecamatan Trimurjo Kabupaten Lampung Tengah. Skripsi jurusan Manajemen Pendidikan Islam Universitas Islam Negeri Raden Intan Lampung.

Yang Y. 2013. Principals' Transformational Leadership in School Improvement. Journal of Academic Administration in Higher Education. Vol.9. Issue. 2. 